\title{
Treatment guidelines for acute mania
}

\author{
Jose Goigolea*, Eduard Vieta \\ From $1^{\text {st }}$ International Congress on Neurobiology and Clinical Psychopharmacology and European \\ Psychiatric Association Conference on Treatment Guidance \\ Thessaloniki, Greece. 19-22 November 2009
}

Nowadays, psychiatrists have a wide range of treatment choices to treat acute mania. Introduction of atypical antipsychotics in the last decade has increased the range of available treatments. A good number of double-blind randomized clinical trials have supported the efficacy of several atypicals, (aripiprazole, olanzapine, quetiapine, risperidone, ziprasidone) both as monotherapy and in combination with lithium or valproate. I.m. formulations of aripiprazole and olanzapine have also shown efficacy in agitated patients suffering acute mania. More recently, asenapine (both as monotherapy or combination) and paliperidone (only monotherapy so far) have shown positive results and may deserve a second-line option according to the most recent clinical guidelines. Atypicals are recommended over typical antipsychotics due to a better short-term side-effect profile. Although not yet proved in meta-analysis, several trials show that atypicals also have a lower risk of switch to depression.

More "classical" mood-stabilizers, such as lithium, valproate, and carbamazepine also share evidence-based antimanic properties. However, some data show lithium being slightly slower in his action, and carbamazepine not being advisable in combination (negative results with risperidone and olanzapine, and not tested with other atypicals). Clinical guidelines usually recommend monotherapy with an antimanic agent to treat mild or moderate mania, and combination treatment (usually with lithium or valproate plus an atypical antipsychotic) for more severe mania. However, combination treatment is usually the rule in clinical practice, especially when the patient is already taking a mood-stabilizer with antimanic action, taking for granted adherence has been demonstrated. Pros and cons of these different approaches will be discussed, as well as differences among antimanic treatment combinations. The use of benzodiazepines in the short-term, for managament of insomnia and psychomotor agitation is also a

Bipolar Disorders Program of the Hospital Clinic, Barcelona, Spain recommended strategy in most guidelines. For treatment resistant mania, there is some evidence supporting the use of clozapine, and ECT may also be a good option. Novel treatments, such as tamoxifen, with four small positive randomized clinical trials, suggest new mechanisms of action that could be further understood in next years.

Published: 22 April 2010

\section{References}

1. Yatham LN, Kennedy SH, Schaffer A, Parikh SV, Beaulieu S, O'Donovan C, et al: Canadian Network for Mood and Anxiety Treatments (CANMAT) and International Society for Bipolar Disorders (ISBD) collaborative update of CANMAT guidelines for the management of patients with bipolar disorder: update 2009. Bipolar Disord 2009, 11:225-55.

2. Grunze H, Vieta E, Goodwin GM, Bowden C, Licht RW, Moller HJ, Kasper S: The World Federation of Societies of Biological Psychiatry (WFSBP) Guidelines for the Biological Treatment of Bipolar Disorders: Update 2009 on the Treatment of Acute Mania. World J Biol Psychiatry 2009, 10:85-116.

3. Goodwin G, Consensus Group of the British Association for Psychopharmacology: Evidence-based guidelines for treating bipolar disorder: revised second edition-recommendations from the British Association for Psychopharmacology. J Psychopharmacol 2009, 23:346-88.

4. Fountoulakis KN, Vieta E: Treatment of bipolar disorder: a systematic review of available data and clinical perspectives. Int J Neuropsychopharmacol 2008, 11:999-1029.

doi:10.1186/1744-859X-9-S1-S62

Cite this article as: Goigolea and Vieta: Treatment guidelines for acute mania. Annals of General Psychiatry 2010 9(Suppl 1):S62.

\section{Submit your next manuscript to BioMed Central} and take full advantage of:

- Convenient online submission

- Thorough peer review

- No space constraints or color figure charges

- Immediate publication on acceptance

- Inclusion in PubMed, CAS, Scopus and Google Scholar

- Research which is freely available for redistribution 